\title{
A valorização total do espaço: capitalismo e geografia em Civilisation Matérielle, Economie et capitalisme - XV-XVIII
}

\author{
The complete valorization of space: \\ capitalism and geography from Civilisation Matérielle, \\ Economie et Capitalisme - XV-XVIII
}

Guilherme Ribeiro

Introdução: Braudel, o espaço geográfico e a escala mundo

Parte do título deste artigo mantém certo parentesco com o vocabulário marxista. Pensamos, sobretudo, na proposição dos brasileiros Antônio Carlos Robert Moraes e Wanderlei Messias da Costa (Moraes \& Costa, 1982, 1984) em

Este artigo é parte integrante da tese de doutorado Espaço, Tempo e Epistemologia no Século XX: a Geografia na obra de Fernand Braudel, laureada com o Prêmio Capes de Tese (edição 2009) na área de Geografia. Agradeço a interlocução com os integrantes do Núcleo de Pesquisa Espaço e Economia (NUPEE), no qual sou co-líder. Guilherme Ribeiro é doutor em Geografia pela Universidade Federal Fluminense (UFF), com estágio doutoral pela Universidade de Paris IV-Sorbonne, e professor adjunto I do Instituto de Ciências da Sociedade e Desenvolvimento Regional da UFF - Campos dos Goytacazes, Brasil (geofilos@ig.com.br). Artigo recebido em 30 de agosto de 2010 e aprovado para publicação em 29 de março de 2011. 


\section{Guilherme Ribeiro}

assimilar a Geografia como o estudo dos processos de valorização do espaço. Todavia, o projeto braudeliano vai além da consideração (não menos interessante, diga-se de passagem) do espaço sob o viés da economia política, embora Les feux de l'Échange e Le Temps du Monde - volumes II e III de Civilisation Matérielle, Économie et Capitalisme - XV-XVIII permitam algumas aproximações com determinadas interpretações "espaciais" provenientes do marxismo. Tocaremos nesse ponto mais adiante.

Se a valorização do espaço não é só de caráter econômico, de que tipo de valorização estamos falando? Mais do que o espaço como uma necessidade básica, trata-se de vê-lo como algo que, ao ser trabalhado e organizado, torna-se um bônus, uma vantagem, um privilégio. E, portanto, seja entre nações, seja no interior dos Estados territoriais, é objeto de contendas. O que Braudel vai mostrar é como a superfície terrestre se humaniza, tornando-se densa através da constituição de uma infraestrutura espacial formada pelos mais variados tipos de construções e objetos. Eis o que ele entende por espaço: um produto da ação humana e, portanto, algo histórico e a ser historicizado.

Nesse caminho, Braudel inverte a perspectiva de Durkheim e aprofunda os esforços de Vidal de la Blache: o espaço não é somente o substrato da vida social, mas uma estrutura que interfere nos rumos do processo histórico em sua totalidade. A espessura do espaço é revestida de historicidade; apreendê-la significa dilatar o processo histórico em si mesmo. Seus sentidos e suas representações não se encerram no meio geográfico, longe disso. Dependendo da perspectiva adotada, o espaço é político, social, simbólico e econômico, variando em seus sentidos e em suas funções. "Mas não inteiramente" (Braudel, 1996b: 12), pois, de qualquer forma e em qualquer variável analisada, o espaço sempre constará como uma problemática a ser levada em conta. Independente do objeto, ele é uma estrutura, ou seja, um item de resistência às mudanças rápidas, a matéria-prima imprescindível que ocupa todos os andares de uma história edificada num ritmo multissecular. ${ }^{1}$ Não por acaso, ocupa lugar nuclear na escrita histórica braudeliana.

Todavia, debruçando-se apenas em Le Temps du Monde, fica mais fácil compreender por que os estudiosos de Braudel negligenciaram ou pouco avançaram no que diz respeito ao espaço. Quão ampla e intricada é tal tarefa! Além dos inúmeros e variados exemplos, ao lançar mão de temas e conceitos como circulação, redes, trajetos, escalas, cidades, Estados e economias-mundo, Braudel situa o espaço no cerne de sua original interpretação econômica do mundo moderno. Não estamos falando de casos isolados e arbitrários, retirados aleatoriamente da incomensurável quantidade de fontes por ele reunida, mas sim de uma "resposta" à démarche analítica em torno dos três andares da vida econômica. A historiadora brasileira Rosângela Vieira costura sua tese de doutorado um pouco dessa 
maneira, examinando como os fundamentos historiográficos de Braudel nortearam sua leitura sobre o capitalismo em Civilisation Matérielle (Vieira, 2002).

Talvez possamos dizer o mesmo acerca da Geografia. Em Les Structures du Quotidien, ao identificar as atividades básicas de subsistência, o autor supracitado enfatizou os laços dos homens com seus ambientes, descrevendo os usos dos solos, das técnicas e dos recursos naturais em geral. É uma Geografia mais camponesa, ligada à terra e aos processos mais simples e iniciais de organização espacial na modernidade (Braudel, 1996a). Em Les feux de l'Échange - quando a moeda, o crédito, os intercâmbios para além do raio local e a economia de mercado como um todo entram em cena - são descritas as constituição de redes, seus circuitos e as articulações escalares aí envolvidas (Braudel, 1996b). Por fim, ao explorar os Estados-nação, a atuação global das grandes companhias e o jogo especulativo típico do capitalismo, Le Temps $d u$ Monde aporta ao debate a espacialidade das economias-mundo, a formação dos mercados nacionais, a circulação e as desigualdades entre os lugares provocadas pela divisão internacional do trabalho. Como se não bastasse, este volume ensaia, ainda que de forma não sistemática e mesmo não intencional (mas cujo conteúdo é bastante relevante), algumas proposições que podem muito bem ser consideradas de natureza epistemológica, no que se refere ao "funcionamento" do espaço em tempos modernos (Braudel, 1996c).

A origem desta "variação" geográfica é dupla. De um lado, o estudo das relações homem-meio, da cultura material observada através das paisagens, de uma dinâmica temporal bastante semelhante ao que Braudel denominaria de longa duração. São as referências da Escola Francesa de Geografia que lhe fizeram a cabeça (mais do que a maioria de seus professores de História, nos tempos da Sorbonne): Jean Brunhes, Albert Demangeon, Pierre Monbeig e, evidentemente, Paul Vidal de la Blanche. De outro lado, a tradição geográfica alemã, da qual Braudel extrairá o trinômio Raum, Wirtschaft e Gesellschaft (espaço, economia e sociedade) (Braudel, 1997; Ribeiro, 2008: 171-185).

Assim, o que emerge de Civilisation Matérielle é uma perspectiva espacial que ultrapassa as abordagens habituais. Tendo como fio condutor o movimento da economia, não se trata da soma de partes isoladas, mas da cuidadosa montagem de um quebra-cabeças, em que cada peça (pesquisada e situada acuradamente) tem seu valor perante as demais, mas que somente em conjunto são capazes de revelar o movimento da história que resultou na constituição de uma economia verdadeiramente global. Sabemos bem que Braudel teve contribuição decisiva em nossa maneira de conceber o tempo. Supondo que tal constatação seja legítima, pode-se dizer algo semelhante sobre o espaço.

Observando atentamente seu enfoque espacial, a lição que fica aos geógrafos é que não há motivo nem para se encerrar nas escalas regional e nacional, 


\section{Guilherme Ribeiro}

nem para temer a escala mundial. ${ }^{2}$ Além disso, Braudel mostra como esta última deve ser estudada: como uma construção, e não como um dado pronto tal como o mapa-múndi apresenta o globo terrestre e seus países, feito estátua sem escultor. Em outras palavras, suas reflexões impactaram não apenas a noção de tempo, mas também a noção de espaço, seja admitindo-o como algo apropriado historicamente, averiguando o movimento das fronteiras econômicas, seja conjugando os lugares uns com os outros, a fim de superar explicações restritas e insuficientes.

Graças a esse esforço de apreensão do mundo como locus de estudos, ele antecipa em muito os apelos de Ortiz e de Beck acerca da necessidade de ultrapassar o quadro nacional no qual as Ciências Sociais insistem em permanecer, mesmo em tempos de globalização (Ortiz, 2003; Beck, 1998). Eis a importância do espaço. Se sair dos territórios nacionais para alcançar o plano mundial é, inequivocamente, uma mudança de escala - mudança que representou um avanço crucial no que concerne às possibilidades de exploração do terreno histórico -, eis que o espaço possui não apenas papel empírico, mas, sobretudo, papel epistemológico central no pensamento braudeliano:

O espaço, fonte de explicação, põe em causa ao mesmo tempo todas as realidades da história, todas as partes envolvidas da extensão: os Estados, as sociedades, as culturas, as economias... E conforme escolhamos um ou outro destes conjuntos, modificar-se-ão o significado e o papel do espaço. Mas não inteiramente (Braudel, 1996c: 12, grifo nosso).

Nesse sentido, podemos sustentar que ver sua fortuna intelectual apenas do ponto de vista temporal é uma limitação. Afinal, se ele revela que o tempo possui variados ritmos, sublinha que o espaço varia de acordo com aquilo que será posto em questão, se combate a rigidez do tempo linear, mostra também que o espaço possui suas hierarquias e, em se opondo à restrição da cronologia, volta-se igualmente contra a insuficiência da escala regional como quadro geográfico por excelência.

Nessa mesma direção (isto é, a de ampliar, e não reduzir, o legado do historiador francês), ver a géohistoire essencialmente como um operador do tempo imóvel (cf. Dosse, 2004) também é uma limitação. Civilisation Matérielle é a prova cabal de que a géohistoire é, além do estudo ampliado das relações homem-meio, uma ferramenta de análise das múltiplas escalaridades criadas pelas práticas econômicas modernas. É isso o que Braudel nos ensina: as transformações do meio, dadas pela técnica, cultura e trabalho, enraízam as civilizações em seus respectivos espaços; a leveza das cidades-Estado tem sua importância histórica garanti- 
da, mas serão substituídas pelos poderosos e "pesados" Estados territoriais, ${ }^{3}$ portadores tanto de poder econômico quanto político; os impérios e as multinacionais, na ambição que as anima, logo tratarão de tecer e fixar suas redes ao redor do mundo, deixando para trás os obstáculos de transportes que impediam a materialização do mundo como escala privilegiada de atuação.

O que Braudel faz éligar povos, culturas e lugares uns aos outros, aproximando-os, mas sem deixar de reconhecer suas diferenças e desigualdades. Para ele, o espaço, sendo histórico, é movimento: as grandes feiras que, por toda a Europa, atraíam pessoas, dinheiro e crédito; a divisão do trabalho, provocando desequilíbrios entre as regiões e países; a descoberta da América e a transposição da Europa junto a novas culturas, civilizações e ambientes; a alternância dos polos hegemônicos de poder; o alcance e a força político-econômica da Companhia das Índias Orientais e dos Függer; o lento processo de ocupação de territórios imensos como os do Brasil e Estados Unidos...

Se uma das grandes polêmicas que dividiu os geógrafos marxistas nas décadas de 1970 e 1980 era se havia ou não uma dimensão geográfica nos escritos de Marx (Lacoste, 1988; Soja, 1993; Quaini, 1979; Harvey, 1996; Smith, 1988; Santos, 1982), esta é uma questão que, no caso de Braudel, jamais se colocaria! Todavia, a sedução exercida pelo materialismo histórico-dialético em uma disciplina tradicionalmente entrelaçada ao status quo fez com que a reflexão do historiador francês, a despeito de sua rica espacialidade, passasse totalmente despercebida. Pode-se constatar tal situação através, ironicamente, de um dos principais artífices da Geografia marxista: Lacoste não lamenta ter descoberto a obra de Braudel tardiamente? (Lacoste, 1989).

Ora, se o idealizador de Hérodote estava preocupado, em termos políticos, em denunciar o uso opressivo e ganancioso do conhecimento geográfico pelo Estado e pelas empresas capitalistas e, em termos epistemológicos, em atentar para o fato de que uma alteração de escala significava uma alteração qualitativa na natureza de um dado fenômeno, Civilisation Matérielle representava um importante foco de debate. ${ }^{4}$ Embora a escrita histórica braudeliana fosse arquitetada por fora da luta de classes, nem por isso ela deixava de observar as tensas operações estratégicas de organização das fronteiras nacionais pelos Estados territoriais e, num outro plano, a expansão de impérios e multinacionais lançando suas redes econômicas e militares mundo afora. Ou seja, assim como Lacoste, Braudel também desnuda o poder de quem controla e domina o espaço. Se evocarmos o nome de outro pensador marxista que muito inspirou os geógrafos que compartilhavam dessa corrente, veremos que um dos principais argumentos de Lefebvre - a reprodução do capitalismo é dada pela produção do espaço (Lefebvre, 2008) - também encontra eco, mutatis mutandis, na pena de Braudel. 


\section{Guilherme Ribeiro}

Não é essa a ideia quando o historiador francês destaca o fim das antigas economias de dominação urbana (Gênova, Veneza, Antuérpia, Amsterdam), causado pela edificação dos Estados nacionais (Portugal, Espanha, França, Inglaterra)? Ou quando situa o capitalismo como um dos principais promotores da modernidade à escala global? No limite, se quiséssemos deixar os intermediários de lado e reunir diretamente Marx e Braudel no que tange ao espaço, malgrado a inconciliável diferença entre ambos sobre a definição de capitalismo, o historiador francês parece repetir a fórmula do filósofo alemão de que o capitalismo, por sua própria essência, só se sustenta operando em escala mundial. ${ }^{5}$

\section{O conceito de economia-mundo e sua constituição espacial}

Passemos ao exame do espaço em Les Feux de l'Échange e Le Temps du Monde. ${ }^{6}$ Podemos iniciar pelo tratamento dado ao conceito de économie-monde, tradução do historiador francês para a palavra alemã Weltwirtschaft. Diferenciando-a da expressão "economia mundial", aquela seria não o todo, mas uma fração do universo dotada de tamanha coerência econômica a ponto de bastar-se por si mesma. Embora afirme que, de todas as abordagens sobre o espaço, a econômica seja a de maior amplitude (a mais fácil, porém, de situar), Braudel, quando evoca o Mediterrâneo do século XVI, aponta que uma das principais características dessa economia-mundo foi ter transposto os limites políticos e culturais que diversificavam e fragmentavam aquela área (Braudel, 1996c: 12-14). Ora, não é o que também ocorre (talvez dissesse Braudel, para reforçar a força da longa duração, "ainda ocorre") nos dias de hoje, quando o poder e o alcance das grandes corporações suplantam a política dos Estados-nação e incorporam a especificidade cultural dos povos, tornando-a mercadoria?

Ao definir as economias-mundo, nota-se o quanto seu conteúdo é carregado de espacialidade:

uma economia-mundo é uma soma de espaços individualizados, econômicos e não-econômicos, agrupados por ela; representa uma enorme superfície (em princípio, é a mais vasta zona de coerência, em determinada época, em uma região determinada do globo) que, habitualmente, transcende os limites dos outros grupos maciços da história (Braudel, 1996c: 14).

Como se não bastasse, ao propor a existência de "regras tendenciais" para as economias-mundo, Braudel aprofunda ainda mais esse conteúdo, enfati- 
zando que elas possuem sempre uma cidade dominante e que suas zonas são hierarquizadas. Por conta desse último aspecto, discordará do modelo de Von Thunen (embora o aprecie) por não ter incorporado a desigualdade espacial (Braudel, 1996c: 29). ${ }^{7}$ E é levando em conta esta desigualdade que ele reconhecerá, pelo menos, três níveis espaciais no plano mundial: centro, periferia e semi-periferia.

O centro, o "coração", reúne tudo o que há de mais avançado e de mais diversificado. $\mathrm{O}$ anel seguinte só tem uma parte dessas vantagens, embora participe delas: é a zona dos "brilhantes secundários”. A imensa periferia, com os seus povoamentos pouco densos, é, pelo contrário, o arcaísmo, o atraso, a exploração fácil por parte dos outros. Essa geografia discriminatória ainda hoje logra e explica a história geral do mundo, se bem que esta, ocasionalmente, também crie por si mesma o logro com a sua conivência (Braudel, 1996c: 29).

Mais adiante, um tópico merece destaque. Embora ele admita zonas economicamente neutras, "quase fora das trocas e das misturas" (Braudel, 1996c: 32), Les Feux de l'Échange confessava, num item sugestivo chamado "Os mercados têm sua geografia", que nenhum espaço era neutro, no sentido de não ser "modificado ou organizado pelo homem" (Braudel, 1996b:156). Estaríamos diante de uma contradição? Não cremos. O que seu autor tem em mente é que, embora haja espaços sem significação econômica, eles sempre terão um papel social. Afinal, embora seus limites não sejam necessariamente idênticos aos limites culturais, as economias-mundo "tendem a compartilhar de uma mesma cultura" (Braudel, 1996c: 53). Não é a conquista do Novo Mundo, ao mesmo tempo que dominação econômica, "a expansão da civilização europeia sob todas as suas formas, algo que suporta e garante a expansão colonial"? (Braudel, 1996c: 54).

Eis que vemos Braudel rechaçar um dos principais problemas das Ciências Sociais no século XX: o economicismo. É por isso que ele percorre temas como moda, técnica, religião e paisagem, pois uma interpretação sobre o capitalismo à luz da herança annaliste deve, antes de tudo, fazer valer o primado da sociedade no entendimento dos demais aspectos. Em última instância, não entende ele que a desigualdade econômica deve-se, antes de mais nada, à desigualdade social? (Braudel, 1989:79). Daí nosso desacordo com o historiador russo Guriêvitch, que se mostra "perplexo" com o que qualifica de "determinismo econômico-geográfico" de Braudel, desaprova sua preferência pelo termo economia social a história social, ressalta que tanto La Méditerranée quanto 


\section{Guilherme Ribeiro}

Civilisation Matérielle negligenciaram a história das mentalidades proveniente de Bloch e Febvre, e vê a geohistória como "uma combinação do materialismo econômico com o determinismo geográfico" (Guriêvitch, 2003:101).

Gostaríamos de sugerir uma outra linha de raciocínio. Se Braudel deixou de lado a história das mentalidades, o fez somente enquanto domínio especializado de pesquisas, visto que não olvidou os componentes mentais e culturais das civilizações em sua fundamentação econômica, sobretudo em Les Structures e em Grammaire des Civilisations (Braudel, 1996a, 2004; Ribeiro, 2011a, 2011b). A opção por "economia social" é tão somente o esforço de insistir numa abordagem social (e, portanto, histórica), e não "econométrica"/quantitativa da economia.

Por último, além de emprestar um caráter pejorativo tanto ao "materialismo econômico" quanto ao "determinismo geográfico", sabemos que o determinismo ao qual Braudel é tantas vezes atrelado está longe de ser algo simplista e facilmente descartado. Nossa leitura é a de que, para ele, o determinismo não é uma noção mecânica e ingênua, tal como aquelas que levaram alguns intelectuais do século XIX a sustentar, entre outras afirmações, que a psicologia dos povos estava diretamente ligada ao clima ou que os habitantes dos trópicos eram mais preguiçosos que os das áreas temperadas. Não há nenhum fundo evolucionista a chancelar a superioridade de uma raça ou civilização em detrimento da outra. $\mathrm{O}$ "determinismo geográfico braudeliano" não é outra coisa senão a evidência de que os aspectos naturais não estão separados e isolados das atividades humanas: eles fazem parte de um todo no qual o clima, o relevo, a hidrografia, o sítio e a posição jogam papel crucial na história das sociedades.

Assim sendo, em certas situações e períodos, o meio determina esta ou aquela decisão, esta ou aquela resposta que, segundo as possibilidades técnicas que as sociedades dispõem, levaram a tomá-las. Segundo Braudel, alimentação, agricultura, produção de mercadorias, vestimentas, crenças, economia, enfim, o conjunto da vida social é indissociável do meio. Aliás, "meio" não é somente o conjunto das características naturais, mas sim uma unidade física e humana, ao mesmo tempo. Ao examiná-lo, ele não está à procura das "influências" exercidas sobre a história, tal como as abordagens ingênuas do século XIX e, mesmo, a "introdução geográfica à história" projetada por Bloch e Febvre (Ribeiro, 2009a, 2009b). Não significa ver os elementos físicos como algo “exterior", os elementos humanos como algo "interior" e, a partir de então, procurar as influências que aqueles exerceriam sobre estes. Destacar cidades, ilhas e paisagens não quer dizer, tampouco, erigir uma história sem sujeitos, mas sim um recurso que visa restituir a ação humana em sua totalidade. Tem a ver também com sua concepção de História enquanto algo que se repete, que se constrói lentamente e com obstáculos estruturais (Ribeiro, 2008: 219-220). 
A despeito daquelas críticas, o esquema das economias-mundo sinaliza um passo essencial no intuito de extrair os condicionantes geográficos do desenvolvimento capitalista. Pensamos também que, embora Braudel tenha acentuado a importância tanto de uma abordagem temporal quanto espacial, analisar o capitalismo segundo as alternâncias das economias-mundo não deixa de ser mais uma alternativa ao ponto de vista marxista. Ainda que a reflexão braudeliana não seja plena de elementos teórico-filosóficos como a de Marx, e que, de uma forma ou de outra, tenha sido moldada à luz dos avanços logrados pelo autor d'O Capital, nela não encontramos a rigidez espacial e o "etapismo" que, embora parcialmente, afetaram o pensamento marxiano. Evidentemente que as condições de trabalho (o contraste entre o Braudel conhecedor de depósitos de documentos ao redor de boa parte do mundo e os empecilhos de toda sorte que Marx enfrentou para empreender suas pesquisas na Prússia, Inglaterra e França, bem como a organização de Arquivos Nacionais que tomaram forte impulso no final do século XIX e que foram cruciais para os avanços da ciência histórica), o contexto epistemológico (a fertilidade e os progressos das Ciências Sociais na primeira metade do século XX) e o momento histórico (de expansão do capitalismo após a Segunda Guerra Mundial em direção aos países do Terceiro Mundo) favoreceram plenamente o historiador francês e, portanto, qualquer comparação que não leve em conta estes aspectos carecerá de credibilidade.

Todavia, ao não eleger nem um polo geográfico (a Inglaterra) nem histórico (a Revolução Industrial), preferindo acompanhar a trajetória de cidades-Estado como Gênova, Veneza, Antuérpia, Amsterdam, a construção dos mercados nacionais da França e da Inglaterra e as economias-mundo da Europa, Império Turco, Rússia e Extremo Oriente (apenas para citar alguns exemplos de Le Temps du Monde), Braudel "descentraliza" tanto a análise quanto a própria narrativa que dá forma à sua reflexão. Ao estudar detalhadamente a mudança de eixo econômico do Mediterrâneo para o Atlântico entre os séculos XV e XVII, a perda de poder das cidades-Estado para os Estados nacionais, a unificação dos territórios através de redes de transportes e comunicações e a materialização do mundo como locus privilegiado de obtenção do lucro por uma minoria de capitalistas - suplantando, assim, os limites escalares da civilização material e da economia de mercado -, ele reconheceu que não estava diante de meros epifenômenos, mas sim de fenômenos de natureza qualitativa, que jogaram papel primordial no desenrolar do processo histórico formador da política, da economia, da sociedade e da cultura em que vivemos. Uma mudança histórica tem suas consequências espaciais, decerto. Mas uma mudança espacial também provoca consequências históricas! Comparando o Mediterrâneo do século XVI com o dos séculos XVII e XVIII, ele elucida a constituição das economias-mundo e a distinção entre economia de mercado e capitalismo. 


\section{Guilherme Ribeiro}

De maneira rasa e ao sabor da corrente, séculos e séculos organizaram cadeias de mercado locais e regionais. Essa economia local que gira por si mesma segundo as suas rotinas está destinada a ser periodicamente objeto de uma zona e de uma cidade dominantes, e isso por um ou dois séculos, até o surgimento de um novo "organizador". É como se a centralização e a concentração dos recursos e das riquezas se processassem necessariamente a favor de certos lugares de eleição da acumulação (Braudel, 1996c: 26).

No mesmo sentido, ao tentar entender a preeminência do capitalismo em Amsterdam, lança mão de uma visada marcadamente espacial e interroga: "Como é que esse centro do mundo está ligado às zonas da economia-mundo que ele domina de perto e de longe?” (Braudel, 1996c: 216). A resposta poderia ser assim sintetizada: com suas importantes cidades dominantes (Fourquet, 1991), seus desníveis espaciais e o capitalismo que as anima, as economias-mundo são costuradas por dentro, através de uma malha de redes e de uma articulação escalar que, juntas, emprestam a dinâmica necessária ao funcionamento pleno da busca do lucro.

Apenas a título de comparação, em Marx o tempo ocupa posição-chave (ao lado, obviamente, de outras noções): o esforço técnico em diminuir o tempo da produção, a mais-valia como o tempo de trabalho no qual o proletário foi explorado pelo burguês, a minimização do tempo de consumo etc. (Marx, 1975). Em Braudel, é o espaço que detém tal posto: a circulação das mercadorias, as distâncias no interior dos territórios afetando o mercado nacional, as redes que viabilizam o comércio global... Não se trata apenas de citar cidades e países e distribuí-los num mapa "em anexo", nem tampouco vislumbrar o espaço como um palco físico onde acontece a movimentação da vida em geral, mas de pensar a economia a partir do espaço:

Essas unidades provinciais, suficientemente extensas para serem mais ou menos homogêneas, são, de fato, antigas nações de tamanho menor que constituíram ou tentaram constituir seus mercados nacionais - digamos, para marcar a diferença [refere-se ao Estado territorial]: seus mercados regionais. Parece até que podemos ver no destino do espaço provincial, mutatis mutandis, uma prefiguração, um duplo destino nacional e mesmo internacional. Repetem-se as mesmas regularidades, os mesmos processos. O mercado nacional é, tal como a economia-mundo, superestrutura e invólucro. O que também é, na sua própria esfera, o 
mercado provincial. Isso quer dizer que uma província foi anteriormente uma economia nacional, até mesmo uma economia-mundo em ponto pequeno; que, a despeito da diferença de escalas, todo o discurso teórico que abria este livro deveria se repetir, palavra por palavra, a seu respeito; que ela comporta zonas regionais e cidades dominantes, "regiões" e elementos periféricos, zonas mais ou menos desenvolvidas, outras quase autárquicas... É, aliás, dessas diversidades complementares, do seu leque aberto que zonas bastante vastas extraíram sua coerência (Braudel, 1996c: 263-264).

Falando não apenas como historiador, mas como historiador profundamente interessado em Geografia, Braudel ensaia reconstituir parte da espacialidade econômica francesa, pois, como havia esboçado no volume anterior de Civilisation Matérielle, uma "geografia retrospectiva explica muitas coisas" (Braudel, 1996b: 507). E foi exatamente utilizando este recurso que ele pôde compreender, com maior nitidez, o desenho espacial assumido pela economia em seu país nos séculos seguintes. Em um determinado trecho, Braudel oferece-nos a trajetória histórica das escalas econômicas da França:

Mas um mercado provincial autônomo não corresponderia a uma economia estagnada? Ele precisa se abrir, por bem ou por mal, aos mercados externos, nacional ou internacional. Por isso mesmo as moedas estrangeiras são, apesar de tudo, uma contribuição revigorante para a Lorena do século XVIII, que já não cunha sua própria moeda e onde o contrabando é uma indústria próspera. Mesmo as províncias mais pobres, que quase nada têm para oferecer e para comprar fora, têm o recurso de exportar mão-de-obra, como a Savóia, o Auvergne ou o Limousin. Com o século XVII, cada vez mais a abertura para fora e os movimentos de balança se tornam importantes, têm valor de indicadores. Aliás, nessa época, com a ascensão dos Estados, com o desenvolvimento da economia e das relações a grande distância, certamente está ultrapassada a hora das excelências provinciais. Seu destino a longo prazo é fundir-se numa unidade nacional, sejam quais forem suas resistências e aversões. Em 1768, nas condições que sabemos, a Córsega torna-se francesa, mas, com toda a evidência, ela não podia sonhar em ser independente. Nem por isso o particularismo provincial morreu; existe ainda hoje, na Córsega e em outros lugares, com muitas consequências, muitos recuos (Braudel, 1996c: 264-65). 


\section{Guilherme Ribeiro}

Em todo caso, ao persistir na relevância das ligações, das trocas e da circulação em geral, nota-se como as questões geográficas são parte indissociável de sua grade de leitura. ${ }^{8}$ Quando aponta o espraiamento da economia a partir de um polo irradiador e a hinterlândia que então se desenha, ele faz valer as marcas de sua formação intelectual e de suas leituras no cativeiro, evidenciando a atração causada pelo pensamento alemão - representados aqui pela teoria dos lugares centrais de Christaller e a teoria da localização industrial de Losch (Braudel, 1996a: 97-99). Porém, Braudel supera em muito o caráter "modelar" e geométrico dessas teorias: um empreendimento econômico deve saber aparelhar o espaço e administrá-lo em sua totalidade, seja a partir de uma cidade, seja formando mercados regionais que, em conjunto e posteriormente, poderão se desdobrar em mercados nacionais e internacionais. Se, tal como Braudel os concebe, uma das particularidades dos capitalistas é a liberdade de escolha para diversificar seus negócios, ao lermos seus escritos aprendemos que outra das características deste pequeno grupo é a capacidade de mudar de escala sempre que precisar. Direta ou indiretamente, ele nos revela que a sustentação do capitalismo depende não só da habilidade em especular e formar monopólios, mas também do controle e da organização do espaço mundial. ${ }^{9}$ Não é à toa que ele identifica a trajetória do capitalismo de maneira mais espacial que temporal. Afinal, "só pode haver economia-mundo quando a rede tem malhas suficientemente apertadas, quando a troca é suficientemente regular e volumosa para dar vida à zona central" (Braudel, 1996c: 82, grifo nosso).

Enfim, como dissemos noutra ocasião (Ribeiro, 2006), incorporando "o mundo inteiro numa história só" (Morineau, 1989: 51), inspirando argumentos de cunho territoriais em torno dos ciclos sistêmicos de acumulação de capital (Arrighi, 1996: ix-xii) e autorizando uma aproximação com a crítica histórica legada por Marx (Aguirre Rojas, 2000: 79-135), Braudel lança as bases para um diálogo fecundo entre a História e a Geografia. Poucos geógrafos não se orgulhariam de ter escrito Le Temps du Monde. Sobre isso, Paul Claval é taxativo: uma das grandes ideias de Braudel reside na constatação de que o lugar e a organização espacial jogam um papel essencial na vida política e econômica (Claval, 2007). Sua leitura seria muito proveitosa por parte dos geógrafos, pois, "ao invés de falar das bases materiais e espaciais das civilizações ou mostrar que o controle das redes de transporte e comunicações estava na origem dos lucros, ele fixou-se na relação entre espaços políticos e econômicos" (Claval, 2007: 288). Sim, pois por mais que a Geografia quisesse ser vista como uma "superciência", capaz de realizar a síntese das ciências de análise (Moreira, 1980), tenha eleito como palco de estudos os fenômenos ocorridos na superfície terrestre e seja herdeira das cosmografias (Gomes, 1997), foi a História - ou, melhor dizendo, a geohistória de Braudel - que conseguiu explorar e materializar fenômenos sociais, políticos, culturais e econômicos em escala mundial. 


\section{A valorização do espaço}

Se é verdade que a mobilidade econômica é maior que a mobilidade política e a civilizacional (Marx e Engels não proferiram no Manifesto que o capital não tinha pátria, querendo dizer, entre outras coisas, que a escala nacional era insuficiente para conter a ânsia da busca do lucro? [Marx \& Engels, s/d]), nem por isso a valorização do espaço é um processo fácil, seja porque pressupõe, antes de mais nada, domá-lo (ou seja, humanizar a natureza indócil), seja pelo empenho necessário para mantê-lo em pleno funcionamento:

Redes e circuitos desenham um sistema. Como, numa estrada de ferro, o conjunto dos trilhos, das suspensões catenárias portadoras de corrente, do material rodante, do pessoal, tudo está disposto para o movimento. Mas este se mostra um problema em si (Braudel, 1996b: 142).

Por exemplo, "o obstáculo que constitui um sistema de transportes sempre oneroso e sem maleabilidade" (Braudel, 1996b: 142). Logo, onde Braudel localiza o fato marcante na França do século XVIII? Na interligação das economias e na modificação da circulação no território francês (Braudel, 1996b: 153). Se olharmos para a vizinha Alemanha, a situação desenhada é totalmente oposta. Embora tenha tido enormes problemas políticos até a concretização de seu Estado nacional após a guerra franco-prussiana, no campo econômico o dinamismo espacial era sinal de pujança:

A atividade da economia alemã é assinalada por múltiplos sinais, quanto mais não seja pela arrancada precoce dos preços ou pela forma como seu centro de gravidade passa de uma cidade para outra: no princípio do século XV, tudo gira em torno de Ratisbona, no Danúbio; depois, Nuremberg impõe-se; a hora de Augsburgo e de seus mercadores financistas soará mais tarde, no século XVI: tudo se passa como se a Alemanha não cessasse de arrastar a Europa que a rodeia e de se adaptar a ela - e também de se adaptar ao seu próprio destino. O Verlagssystem beneficia-se, na Alemanha, destas condições favoráveis. Se transcrevêssemos num mapa todas as ligações que ele cria, todo o território alemão seria cortado por seus traços múltiplos e finos. Umas após as outras, as atividades prendem-se a essas redes. [No século XVI], firmas colossais - os Fugger, os Welser, os Hochstetter e alguns outros - impressionam a opinião públi- 


\section{Guilherme Ribeiro}

ca com a imensidão de suas redes, mais extensas do que a Alemanha inteira (Braudel, 1996b: 280 e 368, grifo nosso).

De qualquer maneira, a esfera econômica não caminha alheia à esfera política. Embora Braudel não compartilhasse integralmente da assertiva marxiana de que "o Estado Moderno não é senão o comitê gestor dos negócios comuns de toda a burguesia" (Marx \& Engels, s/d), preferindo vê-los ora numa relação de tensão (Braudel, 1989: 122-123), ora de complementaridade (Braudel, 1996b: 578), em sua concepção particular de capitalismo o Estado vai atuar pelo menos em duas frentes: no projeto de arquitetura do mercado nacional e na proximidade que o pequeno grupo dos capitalistas terá com seus negócios e finanças. A dimensão geográfica do primeiro aspecto é inevitável. Em uma longa e sugestiva passagem, as escalas estão em pleno movimento, rearranjadas em virtude da política e da economia. Assim sendo, o mercado nacional é

a coerência econômica adquirida de um dado espaço político, sendo esse espaço de uma certa dimensão, antes de tudo o quadro daquilo a que chamamos o Estado territorial, a que antigamente se preferia chamar o Estado nacional. Uma vez que, nesse quadro, a maturidade política precedeu a maturidade econômica, a questão é saber quando, como e por que razões esses Estados adquiriram, economicamente falando, uma certa coerência interna e a faculdade de se comportar como um conjunto em relação ao resto do mundo. É, em suma, tentar fixar um advento que mudou o curso da história europeia, relegando para segundo plano os conjuntos econômicos de primazia urbana. Essa emergência corresponde forçosamente a uma aceleração da circulação, a um aumento das produções agrícola e não-agrícola, bem como a uma dilatação da demanda geral - condições todas que, em abstrato, poderíamos imaginar adquiridas sem a intervenção do capitalismo, como consequência do transbordamento regular da economia de mercado. Na realidade, esta tende muitas vezes a se manter regional, a se organizar no interior dos limites que lhe propõem as trocas de produções diversificadas e complementares. Passar do mercado regional ao mercado nacional costurando juntas economias de raio bastante curto, quase autônomas e muitas vezes fortemente individualizadas, não tem portanto nada de espontâneo. $\mathrm{O}$ mercado nacional foi uma coerência imposta ao mesmo tempo pela vontade política, nem sempre eficaz na matéria, e pelas tensões capitalistas do comércio, especialmente do comércio extreno e a longa distância. Em geral, uma certa expansão das trocas exteriores precedeu a unificação 
laboriosa do mercado nacional. Eis o que nos leva a pensar que os mercados nacionais devem ter se desenvolvido prioritariamente no centro ou perto do centro de uma economia-mundo, nas próprias malhas do capitalismo. Que houve correlação entre seu desenvolvimento e a geografia diferencial que a progressiva divisão nacional do trabalho implica. Aliás, no sentido inverso, o peso do mercado nacional desempenhou seu papel na luta ininterrupta que opõe os diversos candidatos à dominação do mundo - neste caso, no duelo do século XVIII entre Amsterdam, uma cidade, e a Inglaterra, um "Estado territorial". O mercado nacional foi um dos quadros onde se elaborou, sob o impacto dos fatores internos e externos, uma transformação essencial para o desencadeamento da Revolução Industrial: refiro-me ao crescimento de uma demanda interna múltipla capaz de acelerar a produção nos seus diversos setores, de abrir os caminhos do progresso (Braudel, 1996a: 255-257).

Independente de sua posição anti-estatista - seja do lado capitalista (Braudel, 1989: 134) ou socialista (Braudel, 1996c: 586) -, o historiador francês faz questão de sublinhar os impactos espaciais provocados pela ascensão dos Estados territoriais ante a queda das antigas economias de dominação urbana. $\mathrm{Ou}$, para usarmos os termos alemães e corroborar mais uma vez a influência decisiva do pensamento do outro lado do Reno em sua obra, a oposição entre a Territorialwirtschaft e a Stadtwirtschaft e seus desdobramentos espaciais (Braudel, 1996c: 271-273).

Num primeiro momento, porém, Braudel constata que há muitas semelhanças entre ambas, quer no tocante à ultrapassagem do seu espaço próprio (por isso, p.ex., Veneza e Inglaterra são economias-mundo e potências coloniais), quer no tocante aos meios de dominação e administração do cotidiano (frota, exército, violência, Bancos Centrais). Contudo, elas possuem distintas organizações estruturais: as cidades-Estado contornam os dilemas do setor primário através da importação e sua agricultura, quando existe, enfatiza o grande rendimento típico do capitalismo, ocorrendo, portanto, um pacto assaz "moderno" envolvendo as populações rural e urbana. Além disso, suas indústrias de luxo são, frequentemente, bem-sucedidas. De outro lado, não bastasse o vagar da montagem político-econômica do Territorialwirtschaft, ao contar com uma população majoritariamente rural, precisará investir internamente no domínio agrícola, bem como administrar as finanças, as fronteiras e a coerência econômica em geral.

É diante desse quadro que Braudel observa que as cidades-Estado saíram na frente no que se refere ao sucesso econômico e à tomada de espaços alhe- 


\section{Guilherme Ribeiro}

ios, pois o "Estado territorial em formação tem muito o que fazer para se empenhar de imediato na conquista dos grandes mercados do mundo" (Braudel, 1996c:.273). No entanto, ao conseguir um equilíbrio entre a oferta, a demanda e os diversos setores da economia impostos por um mercado nacional, este se apresenta como um "acréscimo de poder", levando a Inglaterra a superar em muito a Holanda e postular a dominação mundial (Braudel, 1996c: 273; ver também Arrighi, 1996: 213).

Ao trabalhar com o conceito de economia-mundo, Braudel não o concebe, do ponto de vista geográfico, apenas como a delimitação cartográfica dos fenômenos econômicos, mas sim numa perspectiva "vertiginosa" e "ativa" que visa perscrutar como o jogo econômico cria e se reproduz segundo uma determinada lógica espacial:

Colocar-nos-emos sucessivamente em duas perspectivas: primeiro, ao lado do mercador, imaginaremos o que possa ser sua ação, sua tática costumeira; depois, afastando-nos dele, amplamente independentes das vontades individuais, consideraremos os espaços mercantis em si mesmos, os mercados em sentido lato. Sejam eles urbanos, regionais, nacionais ou internacionais, sua realidade impõe-se ao mercador, envolve-lhe a ação, favorece- $a$ ou constrange- $a$. Além disso, eles se transformam ao longo dos séculos. E essa geografia, essa economia variáveis dos mercados (...) remodelam e reorientam incessantemente a ação particular do mercador (Braudel, 1996b: 115, grifo nosso).

Portanto, seria demais afirmar que ele estava bem à frente daquilo que a Geografia Econômica tinha produzido até 1979? Não nos parece um exagero. Um exemplo: onipresentes nos volumes II e III de Civilisation Matérielle, seu autor nos mostra que o uso das redes e das escalas pelo capitalismo não é algo recente. Todavia, não nos parece que antes da década de 1990 as redes tenham tido o status de categoria central entre os geógrafos, ao passo que as escalas, embora estejam tradicionalmente enlaçadas ao pensamento geográfico, nem por isso mereceram a atenção teórico-metodológica devida - o que não significa que não haja contribuições interessantes por parte dos geógrafos (Lacoste, 1988; Haesbaert, 1993; Smith, 2002; Massey, 2004, 2008).

$\mathrm{Na}$ démarche braudeliana, as redes articulam as escalas e lhes conferem movimento, mas não um movimento caótico e desorganizado e sim a gestão política do território pelo Estado e a gestão econômica da circulação de mercadorias e capitais pelo capitalismo. É por intermédio das redes que a escala local pode ser superada ou, melhor dizendo, implodida por dentro graças ao impacto provoca- 
do pela história global. ${ }^{10}$ Assim, $\mathrm{o}$ alcance da rede não significa somente $\mathrm{o}$ aumento de sua extensão, mas uma alteração qualitativa na natureza dos fenômenos ocorridos no âmbito de suas escalas. As redes aproximam os espaços e encurtam os tempos, revelando assim dinâmicas geográficas distintas de acordo com a vida material, a economia de mercado e o capitalismo. Ou, o que é a mesma coisa, elas põem a nu as disputas de poder no e pelo espaço. ${ }^{11}$

Capaz de conjugar, de modo extremamente fecundo, tanto a dimensa $a^{12}$ (o sítio, a situação e o tamanho do território) quanto a dinâmica (interescalaridade e reticularidade) do espaço, cumpre enfatizar que estamos diante de uma abordagem material e plural do mesmo, ora visto como meio de sobrevivência e produto da cultura (a história da longa duração das civilizações), instrumento de controle (as fronteiras do território estatal e a formulação de políticas econômicas nacionais, como o mercantilismo ${ }^{13}$ ) ou ferramenta de potencialização do poder e do dinheiro (os tentáculos dos impérios e das empresas dominando o globo). Nunca é demais enfatizar: é algo difícil de entender como Braudel passou praticamente despercebido pelos geógrafos!

\section{Conclusão}

Pode-se reconhecer que a vida material, a economia de mercado e o capitalismo admitem dinâmicas geográficas específicas, embora mantenham pontos em comum. Assim, gostaríamos de encerrar este artigo lançando mão de um pequeno quadro esquemático que visa ilustrar a riqueza geográfica presente em $\mathrm{Ci}$ vilisation Matérielle. A coluna Aspectos Geográficos contém os itens "Conceitos", "Espaços", "Densidade" e "Espacialidade" que, distribuídos conforme os andares erigidos por Braudel, indicarão as formas e os conteúdos espaciais presentes em Les Structures du Quotidien, Les Feux de l'Échange e Le Temps du Monde. Tal quadro, no entanto, não deve ser encarado de forma rigorosa. É assim que, no item "Conceitos", a rigor talvez seja mais correto falar em "descrição da forma", já que Braudel não explicita o uso do conceito de paisagem. Todavia, seu diálogo com os geógrafos franceses e a proximidade com suas temáticas nos levaram a fazê-lo. Seguindo raciocínio parecido, optamos por não incluir o conceito de redes em Les Feux de l'Échange, já que em Le Temps du Monde ele aparece muito mais vezes e de modo mais explícito no que diz respeito à sua dimensão espacial. No item "Espaços", achamos por bem incluir "mundo", a fim de ressaltar que é efetivamente a ação capitalista que materializa o planeta como referência de seus negócios. E os exemplos poderiam continuar, mas a intenção não é outra senão a de abrir uma janela a explorar os vários nexos entre espaço e economia no pensamento de Fernand Braudel. 
Tabela

\begin{tabular}{|c|c|c|c|}
\hline $\begin{array}{l}\text { Aspectos } \\
\text { Geográficos }\end{array}$ & $\begin{array}{l}\text { Les Structures } \\
\text { du Quotidien }\end{array}$ & Les Feux de l'Échange & Le Temps du Monde \\
\hline Conceitos & Paisagem & $\begin{array}{l}\text { Escalas } \\
\text { Território nacional }\end{array}$ & $\begin{array}{l}\text { Escalas } \\
\text { Território nacional } \\
\text { Redes }\end{array}$ \\
\hline Espaços & $\begin{array}{l}\text { Aldeias } \\
\text { Campos } \\
\text { Pequenas e médias cidades }\end{array}$ & $\begin{array}{l}\text { Feiras } \\
\text { Cidades-Estado } \\
\text { Médias e grandes cidades } \\
\text { Estados-Nação }\end{array}$ & $\begin{array}{l}\text { Cidades-Estado } \\
\text { Grandes cidades } \\
\text { Estados-Nação } \\
\text { Mundo }\end{array}$ \\
\hline Densidade & $\begin{array}{l}\text { Espaços isolados } \\
\text { e com pouca ligação entre si }\end{array}$ & $\begin{array}{l}\text { Espaços interligados mas } \\
\text { com lacunas de } \\
\text { transporte e comunicação }\end{array}$ & $\begin{array}{l}\text { Redes e escalas } \\
\text { bem articuladas }\end{array}$ \\
\hline Espacialidade & Relações homem-meio & $\begin{array}{l}\text { Criação de circuitos } \\
\text { econômicos de médio e } \\
\text { longo alcance }\end{array}$ & $\begin{array}{l}\text { O mundo como palco } \\
\text { central da acumulação } \\
\text { capitalista }\end{array}$ \\
\hline
\end{tabular}

1. Ao examinar as desigualdades econômicas regionais na França, ele assegura que "De fato, nesses problemas de geografia diferencial, como em qualquer outro, as perspectivas diferem segundo os períodos cronológicos em questão. Não haverá, por baixo das mudanças que dependem de uma conjuntura forçosamente lenta, oposições de duração ainda mais longa, como se a França - aliás, qualquer 'nação' não fosse de fato mais do que uma sobreposição de realidades diferentes, sendo as mais profundas (pelo menos as que imagino como mais profundas) por definição, e mesmo por observação, as que levam mais tempo a se desgastar e, portanto, as mais obstinadas em permanecer? Neste caso, a geografia, elucidação indispensável, assinala não sei quantas dessas estruturas, dessas diferenças permanentes: as montanhas e as planícies, o Norte e o Sul, o Leste continental e o Oeste imerso nas brumas do oceano... Estes contrastes pesam tanto e mais sobre os homens quanto as conjunturas econômicas que giram acima delas, ora melhorando, ora desfavorecendo as zonas em que vivem" (Braudel, 1996c: 312-315, grifo nosso, à exceção de "permanentes").

2. A respeito deste tópico, vale a pena consultar o artigo de Jean-Baptiste Arrault, que discute como a expansão do capitalismo e a crise de 1929 impeliram os geógrafos da Escola Francesa de Geografia a estudar a escala mundial. Assim, Arrault contraria a interpretação tão equivocada quanto difundida de que os representantes desta corrente se limitavam à escala regional (Arrault, 2007).

3. Comentando o papel do Mediterrâneo para a economia italiana, Braudel afirma: "Na regressão geral do Ocidente, a Itália é, como dizem os economistas, uma 'zona 


\section{A valorização total do espaço}

protegida': está reservado a ela o melhor dos tráficos; o seu jogo com o ouro, sua experiência em matéria de gestão da moeda e de crédito a protegem; seus Estados-cidades, máquinas de gestão muito mais leve do que a dos pesados Estados territoriais, podem viver ao largo nessa conjuntura restrita. As dificuldades são para os outros, principalmente para os grandes Estados territoriais que sofrem e se desagregam. $\mathrm{O}$ Mediterrâneo e a Europa ativa ficam mais do que nunca reduzidos a arquipélagos de cidades" (Braudel, 1996c: 101).

4. Em mais uma passagem, Braudel afirma: "As formas sociais têm também as suas geografias diferenciais. Até onde vão, por exemplo, no espaço, a escravatura, a servidão, a sociedade feudal? A sociedade muda completamente segundo o espaço" (Braudel, 1996c:.35, grifo nosso). Quando explica o funcionamento espacial das economiamundo, assevera que esta "é uma justaposição de zonas ligadas entre si mas a níveis diferentes. (...) $\mathrm{E}$, obrigatoriamente, as qualidades e características da sociedade, da economia, da técnica, da cultura, da ordem política, mudam conforme nos deslocamos de uma zona para outra" (Braudel, 1996c: 29, grifo nosso). Noutra ocasião, reflete da seguinte forma: "Uma pequena cidade é um bom campo de observação no atual? Sim, sem dúvida, com a condição de que não seja estudada somente por si e em si mesma, segundo as regras praticadas com muita frequência pela investigação etnográfica, mas como um testemunho que é preciso restabelecer em planos múltiplos de comparação, tanto no tempo quanto no espaço. No que concerne a Minas Velhas, seria preciso discutir (...) sua circunvizinhança atual, deter-se em Vila Nova, (...) mas também avançar até Formiga, até Gruta, até Sincora, permanecer aí à vontade e mesmo interrogar o conjunto do Estado da Bahia, suas cidades, suas vilas. Depois, sem dúvida, ir mais longe, no Brasil, alhures talvez..." (Braudel, 2005: 228 [1969]). Não é notória a semelhança com a proposição de Lacoste acerca da espacialidade diferencial? (Lacoste, 1988).

5. Em trecho que lembra parte do espírito do Manifesto Comunista: "Mas, em última instância, nada seria possível sem a ação especial e como que libertadora do mercado mundial. $\mathrm{O}$ comércio de longa distância não é tudo, mas é a passagem obrigatória para um plano superior do lucro. Ao longo de todo o terceiro e último volume desta obra, voltaremos ao papel das economias-mundo, desses espaços fechados que se constituíram como universos particulares, pedaços autônomos do planeta. Têm a sua própria história, pois seus limites foram mudando com o decorrer do tempo, cresceram, ao mesmo tempo que a Europa se lançava à conquista do mundo. Com estas economias-mundo, chegaremos a outro nível da concorrência, a outra escala da dominação. E a regra tantas vezes repetida que, por uma vez, poderemos segui-las sem erro através de uma história cronológica da Europa e do mundo, através de uma sucessão de sistemas mundiais que são, na realidade, a crônica global do capitalismo. Dizia-se outrora mas a fórmula continua boa e diz bem o que quer: a divisão internacional do trabalho e, claro, lucros que dela resultarão" (Braudel, 1996b: 535-536).

6. Em virtude da dimensão geográfica de Les Structures du Quotidien admitir vínculos específicos com a Escola Francesa de Geografia, este livro mereceu atenção particular no artigo Espaço e técnica como estruturas do cotidiano: capitulos braudelianos de história do pensamento geográfico (I) (Ribeiro, 2011). Tal artigo abre uma série de três onde, em função do diálogo de Braudel com a Geografia atravessar toda sua obra e ocupar papel epistemológico central em suas inovações historiográficas, sustentamos a hipótese de que existe um capítulo da história do pensamento geográfico que só pode ser escrito tomando tal obra como objeto de pesquisa. O segundo artigo 
intitula-se $A$ geografia na formação do território francês: capítulos braudelianos de história do pensamento geográfico (II) (Ribeiro, 2010) e o terceiro $A$ gênese da geohistória em Fernand Braudel: capitulos braudelianos de história do pensamento geográfico (III), ainda a ser publicado.

7. Embora o historiador econômico Fritz Rörig tenha sido o primeiro a dotar o termo Weltwirtschaft do sentido de economia-mundo (Braudel, 1996c: 82), "a genealogia teórica do conceito deve ser pesquisada, antes, na transposição à escala planetária do modelo de zonas concêntricas formulado sobre o plano local do micro-sistema pelo economista alemão Von Thunen (1780-1851)" (Gemelli, 1995: 125).

8. Braudel crê que até “a Revolução do século XIX, momento em que se apropriará da produção industrial promovida à categoria do grande lucro, é na circulação que o capitalismo se sente mais em casa" (Braudel,1996b: 200). Mas não é só isso, pois as "condições prévias para o capitalismo dependem da circulação; à primeira vista, quase poderíamos dizer: apenas da circulação. E, quanto mais espaço essa circulação percorre, mais frutuosa é. Esse determinismo elementar atua em toda a parte" (Braudel, 1996b: 500).

9. Ao explanar a situação econômica do Novo Continente no período colonial, assegura que, seja em Lima, Cidade do México ou Recife, "encontramo-nos, na realidade, no tecido das ligações da economia-mundo europeia, que é como uma rede lançada sobre a América inteira. Não no interior de capitalismos nacionais, mas no quadro de um sistema global, manobrado a partir do próprio coração da Europa" (Braudel, 1996c: 397).

10. Analisando o esquema de Von Thunen aplicado na cidade de Caen por Jean-Claude Perrot, Braudel pondera: "O mais significativo não é o jogo duplo entre espaço regional e espaço internacional que a cidade tem de praticar: duas circulações diferentes, a primeira capilar e de curta distância, contínua; a segunda, intermitente e que, em casos de crise alimentar, tem de lançar mão dos transportes fluviais pelo Sena, ou dos tráficos marítimos a partir de Londres e de Amsterdam. Estes dois sistemas se ajustam, se opõem, ou se somam, ou se sucedem. A maneira pela qual a vida internacional afeta uma cidade qualifica-a tanto, e por vezes mais, quanto a sua ligação perene com as que lhe são próximas. $A$ história geral se sobrepõe à história local" (Braudel, 1996c: 61-62, grifo nosso).

11. "Todas as redes, mesmo as mais fortes, conhecem um ou outro dia recuos, oscilações. E qualquer falência de uma rede, em seu centro, transmite suas consequências ao conjunto de suas posições e, talvez mais do que a qualquer outro ponto, à periferia. (...). Todavia, uma rede ativa posta em xeque sempre tem tendência a compensar suas perdas. Rechaçada desta ou daquela região, vai lançar suas potencialidades e seus capitais numa outra. Essa é a regra, pelo menos todas as vezes que está em jogo um capitalismo poderoso e já muito acumulador" (Braudel, 1996c: 138-139).

12. Ao mesmo tempo que enxerga a situação geográfica, Braudel grifa igualmente os circuitos, a hinterlândia e o jogo de escalas: "Talvez uma das vantagens de Veneza tenha sido precisamente o fato de ser mais racional, de correr menos riscos. $\mathrm{E}$ sua situação geográfica favorecia-a, com toda a evidência. Sair da laguna é entrar no Adriático e, para um veneziano, era também ficar em casa. Para um genovês, sair da sua cidade é entrar no mar Tirreno, mar vasto demais para ser eficazmente vigiado e que, na realidade, pertence a todo o mundo. E enquanto o Leste for a principal fonte de riqueza, Veneza, com a facilidade de seu caminho de ilhas para o Oriente, estará em vantagem. Quando a 'rota mongol' se rompeu nos anos 1340, foi ela a primeira a se apresentar, 
antecipando-se aos seus rivais, já em 1343, à porta da Síria e do Egito, e não a encontrou fechada. Finalmente, Veneza, melhor do que qualquer outra cidade italiana, está ligada à Alemanha e à Europa central, que são os clientes mais certos para o algodão, a pimenta, as especiarias e a fonte privilegiada do metal

\section{Referências bibliográficas}

AGUIRRE ROJAS, Carlos Antonio. Os Annales e a Historiografia Francesa: Tradições Críticas de Bloch a Foucault. Maringá: Eduem, 2000.

ARRAULT, Jean-Baptiste. "Géographie et mondialisation. Les géographes français face à la crise des années 1930". Annales de Géographie, n. 657, 2007, p. 493-512.

ARRIGHI, Giovanni. O Longo Século XX: Dinheiro, Poder e as Origens do Nosso Tempo. Rio de Janeiro/São Paulo: Contraponto/ Unesp, 1996 [1994].

BECK, Ulrich. ¿Que és la Globalización? Falácias del Globalismo, Respuestas a la Globalización. Barcelona: Paidós, 1998 [1997].

BRAUDEL, Fernand. Escritos sobre a História. $2^{\mathrm{a}}$ ed. São Paulo: Perspectiva, 2005 [1969].

Civilização Material, Economia e Capitalismo: séculos XV-XVIII. Volume 1: As estruturas do cotidiano. São Paulo: Martins Fontes, 1996a [1967].

Civilização Material, Economia e Capitalismo: séculos XV-XVIII. Volume 2: Os Fogos das Trocas. São Paulo: Martins Fontes, 1996b [1979].

Civilização Material, Economia e Capitalismo: séculos XV-XVIII. Volume 3: O branco, chave do comércio do Levante" (Braudel, 1996c: 103).

13. "O mercantilismo é justamente a tomada de consciência dessa possibilidade de manobrar o conjunto da economia de um país, ou seja, resumindo, a busca já do mercado nacional” (Braudel, 1996c: 271).

Tempo do Mundo. São Paulo: Martins Fontes, 1996c [1979].

- Uma Lição de História. Rio de Janeiro: Jorge Zahar, 1989 [1986].

Gramática das Civilizações. São Paulo: Martins Fontes, 2004 [1963].

Géohistoire: la société, l'espace et le temps. In: BRAUDEL, Fernand. Les ambitions de l'histoire. Édition établie et présentée par Roselyne de Ayala et Paule Braudel. Paris: Éditions de Fallois, 1997 (1941-1944), p. 68-114.

CLAVAL, Paul. Géographie et Géographes. Paris: L'Harmattan, 2007.

FOURQUET, François. Cidades e economias-mundo segundo Fernand Braudel. Espaço Eั Debates, ${ }^{\circ}$ 33, ano XI, 1991, p. 53-62.

GEMELLI, Giuliana. Fernand Braudel. Paris: Odile Jacob, 1995.

GOMES, Paulo César da Costa. Geografia fin-de-siècle: o discurso sobre a ordem espacial do mundo e o fim das ilusões. In: CASTRO, Iná Elias de; CORRÊ, Roberto Lobato \& GOMES, Paulo César (orgs.). Explorações geográficas: percursos no fim do século. Rio de Janeiro: Bertrand Brasil, 1997, p. 13-42. 
GURIÊVITCH, Aaron. A Sintese Histórica e a Escola dos Anais. São Paulo: Perspectiva, 2003 [1991].

HAESBAERT, Rogério. Escalas espaço-temporais: uma introdução. Boletim Fluminense de Geografia. Ano I, vol. 1, no 1, 1993, p. 31-51.

HARVEY, David. Geografia. In: BOTTOMORE, Tom (org.). Dicionário do Pensamento Marxista. Rio de Janeiro: Jorge Zahar Editor, 1996 [1983], p. 162-165.

LACOSTE, Yves. A Geografia - isso serve, em primeiro lugar, para fazer a guerra. Campinas: Papirus, 1988 [1976].

Braudel geógrafo. In: LACOSTE, Yves (coord.). Ler Braudel. São Paulo: Papirus, 1989 [1988], p. 175-219.

LEFEBVRE, Henri. Espaço e Política. Belo Horizonte: Editora da UFMG, 2008 [1972].

MARX, Karl O Capital (Livro 1, Volume 1). Rio de Janeiro: Civilização Brasileira, 1975 [1867].

- ENGELS, Friedrich. O Manifesto Comunista. Textos - Volume 3. São Paulo: Edições Sociais, s/d [1848], p. 13-59.

MORINEAU, Michel. Um grande projeto: civilização material, economia e capitalismo - séculos XV-XVIII. In: LACOSTE, Yves (coord.). Ler Braudel. São Paulo: Papirus, 1989 [1988], p. 31-61.

MASSEY, Doreen. Filosofia e política da espacialidade: algumas consideraçóes. Geographia, Revista do Programa de PósGraduação em Geografia da UFF, ${ }^{\circ} 12$, ano 6,2004, p. 7-23.

Pelo espaço. Uma nova política da espacialidade. Rio de Janeiro: Bertrand Brasil (2008 [2005]).

MORAES, Antonio Carlos Robert \& COSTA, Wanderlei Messias da. $A$ valorização do espaço. São Paulo: Hucitec, 1984.
A geografia e o processo de valorização do espaço. In: SANTOS, Milton (org.). Novos rumos da geografia brasileira. São Paulo: Hucitec, 1982, p. 111-130.

MOREIRA, Ruy. $O$ que é Geografia. São Paulo: Brasiliense, 1980.

ORTIZ, Renato. Mundialização e cultura. São Paulo: Brasiliense, 2003 [1994].

QUAINI, Massimo. Marxismo e geografia. Rio de Janeiro: Paz e Terra, 1979.

RIBEIRO, Guilherme. Epistemologias braudelianas: espaço, tempo e sociedade na construção da geo-história. Geographia, Revista do Programa de Pós-Graduação em Geografia da UFF, n.15, ano 8, 2006, p. 87-114.

Espaço, tempo e epistemologia no século XX: a geografia na obra de Fernand Braudel. Tese (Doutorado em Geografia) Programa de Pós-Graduação em Geografia. Universidade Federal Fluminense, Niterói, 2008.

. A Geografia testemunha a história: paisagem, região e interdisciplinaridade em Marc Bloch. Revista de História Regional, vol. 14, n.2, 2009a, p.7-28.

A Geografia na formação do território francês: capítulos braudelianos de história do pensamento geográfico (II). Confins [On line], 10, 2010, p.1-20.

Para ler Geografia ou A Geografia segundo Lucien Febvre. Terra Livre, vol. 1, n.32, 2009b, p. 121-136.

Espaço e técnica como estruturas do cotidiano: capítulos braudelianos de história do pensamento geográfico (I). Investigaciones Geográficas (UNAM), 2011a, p.58-73.

Fernand Braudel e a geohistória das civilizações. História, Ciências, Saúde Manguinhos, 2011b. 
SANTOS, Milton. Alguns problemas da contribuição marxista à Geografia. In: SANTOS, Milton (org.). Novos rumos da Geografia brasileira. São Paulo: Hucitec, 1982, p. 131-139.

SMITH, Neil. Desenvolvimento desigual: natureza, capital e a produção de espaço. Rio de Janeiro: Bertrand Brasil, 1988 [1984].

- Geografía, diferencia y las políticas de escala. Terra Livre, São Paulo, ano 18, ${ }^{\circ}$ 19, jul./dez., 2002, p. 127-146.
SOJA, Edward. Geografias pós-modernas: a reafirmação do espaço na teoria social crítica. Rio de Janeiro: Jorge Zahar Editor, 1993 [1992].

VIEIRA, Rosângela de Lima. Fernand Braudel: a relação do método historiográfico e o conhecimento histórico. Tese (Doutorado em Geografia) - Faculdade de Ciências e Letras, Universidade Estadual Paulista, Assis, 2002.

\title{
Resumo
}

O objetivo deste artigo é analisar a relação entre espaço e economia em Civilisation Matérielle, Économie et Capitalisme - XV-XVIII (1979) do historiador francês Fernand Braudel (1902-1985). A partir do conceito de economia-mundo, podemos observar o papel crucial do espaço em sua original interpretação sobre o desenvolvimento do capitalismo.

Palavras-chave: espaço; economia; economia-mundo; capitalismo; geografia.

\begin{abstract}
The aim of this article is to analyze the relationship between space and economy in Civilisation Matérielle, Économie et Capitalisme - XV-XVIII by the French historian Fernand Braudel (1902-1985). Taking as a basis the concept of world-economy, we can observe the crucial role that space plays in Braudel's original interpretation on the development of capitalism. Keywords: space; economy; world-economy; capitalism; geography.
\end{abstract}

\section{Résumé}

L'objectif de cet article est analyser les liens entre l'espace et l'économie chez Civilisation Matérielle, Économie et Capitalisme - XV-XVIII de l'historien français Fernand Braudel (1902-1985). A partir du concept d'économie-monde, on peut constater le rôle crucial de l'espace dans son original interprétation sur le développement du capitalisme.

Mots-clés: espace; économie; économie-monde; capitalisme; géographie. 